\title{
Paths and Technologies in the Life Project of People with Disabilities: International Perspectives and Educational Potential
}

\author{
Catia Giaconi ${ }^{\text {a }}$, Noemi Del Bianco ${ }^{\text {b1 }}$ \\ ${ }^{a}$ University of Macerata, Italy, catia.giaconi@unimc.it \\ ${ }^{b}$ University of Macerata, Italy,noemi.delbianco@gmail.com
}

\begin{abstract}
The purpose of this paper was to analyse the core of the quality of life, intended as a complex construct with specific and transversal features. The approach to this issue, by linking it to the great emergency of disability in adulthood, pushes the analysis into deep conceptual pedagogical reflections, which lead the authors' initial reflections to focus on the theoretical framework related to the quality of life model and subsequently on the identification of some areas of intervention as a tangible application of the quality of life model. New perspectives and innovative potentials for the quality of life of adults with disability are investigated to reach new awareness, which can also be applied in different life contexts. The paper mentions meaningful trajectories, also from the international scene, aiming to guarantee significantly oriented life trajectories.
\end{abstract}

Keywords: disability, technologies, life project, quality of life

\section{Introduction}

The ageing of disabled people poses considerable challenges, especially if we consider some emerging phenomena of particular interest, as reported at the international level, concerning the caregiving to adults with disabilities during their lives, using assisted solutions through technologies, to allow greater autonomy and permanence in living contexts. This framework has different interpretations and different levels of complexity. Some authors take into consideration the consequences at the social level, therefore, the effects on individual well-being and the economic and social costs (Thompson et al., 2012). In this case, on the one hand, the interdisciplinary approach, aimed at the implementation of assisted living environments, tends to demonstrate how these solutions can, over time, reduce costs of social and health services that are used to manage the increase in the elderly population with disabilities and on the other hand, in the perspective of special pedagogy, significant educational challenges are added to rethink paths and actions aiming to build life projects under the aegis of the quality of life, where a central role is assigned to assistive technologies and assisted living environments as models of inclusion, independence, participation and well-being (Giaconi, 2014).

In this researching framework, there are several central issues highlighted by the scientific literature that focus its attention on the delicate issue of designing personalised solutions and responding to the quality of life domains for adults with disabilities (Giaconi, 2014; Penne et al., 2012; Maes, Lambrechts, Hostyn and Petry, 2007; Zijlstra and Waskamp, 2007; Cambridge and Cornaby, 2000; Felce et al., 2000). In this regard, pedagogical emergencies concern critical phases, during the growth of people with disabilities, where, even today, risk is resolved with emergency solutions rather than perspectives of growth outlined since childhood (Pavone, 2011). For example, we can consider different transitional phases that can mark, in one way or the other, the future of the disabled person. In fact, the

\footnotetext{
${ }^{1}$ In the shared design of the article, Catia Giaconi has edited the writing of paragraph 1-2-4 and Noemi Del Bianco has edited the writing of paragraph 3 and the related subparagraphs and references.
} 
disabled person and the disabled person's family encounter some critical issues: first in the transition from the period that the person spent in the school contexts to the inclusion in work and social contexts or, in the absence of this possibility, the mere permanence in the family context and afterwards, in the transition from the house, and therefore from the family context, to other realities and housing solutions that do not always suit their needs but respond to the needs to obtain an assistive care. At the end of the educational trail, the person with disabilities runs the risk of an exclusive stay in the family environment that, with the passage of time, may not always provide the right support for a quality life, because of the advanced age of the parents (Blackorby and Wagner, 1996). This situation is often associated with another delicate passage that concerns the loss of the network existing in the school context and, even more, the decline of the family support network for both parents' precarious health conditions or for their death. In this case, the transition from the family home to another family member's house (brothers or sisters) or, very often, to residential structures is a complex step, not sufficiently prepared and not always respectful of personal quality of life.

Over time, the person with disabilities risks, therefore, to have increasingly fewer opportunities for integration and participation in the community. The places usually frequented by people with disabilities are house or, in any case, a restricted social environment; otherwise, if inserted in residential structures, the person risks to frequent only people with disabilities and the places related to the structure. Several studies (Sturmey, 1995; Chen, 1993; McConkey et al., 1981) proved that disabled adults spend most of their free time at home or in large institutions; moreover, during this time, regardless of being alone or with their family members, they are in danger of deteriorating what was acquired previously. It should be also highlighted how adult persons with disabilities, also because of the natural ageing process, may run the risk of an early deterioration of the cognitive functions due to the transition from school integration trails and periods of intense rehabilitation to poor contacts with peers, limited repertoire of recreational and leisure activities, poor work integration and, often, a poor rehabilitation project. These changes have a considerable impact on every person's quality of life, particularly on that of disabled people, in relation to the meaning that the person attributes to the life experience. Therefore, the highly desirable prospect to address the potential risk of marginalisation and social exclusion is suggested by special pedagogy, which proposes the rethinking of inclusive models, capable of guaranteeing adequate levels of quality of life and social participation.

Despite the complexity of the question, there are three crucial issues that we want to address in this contribution:

1. the model of quality of life, to analyse the needs of adults with disabilities;

2. the model of ambient assisted living, as a possibility for inclusion and

3. the design and the personalisation of life trajectories of people with disabilities, supported by assisted technologies.

\section{The quality of life as a perspective of analysis in educational planning}

Numerous studies, focussing on the quality of life model, in the scientific literature, outline a plurality of definitions and numerous procedures considered capable to "measure" the quality of life (Schalock and Verdugo Alonso, 2002; Schalock et al., 2000; Felce and Perry, 1996). The difference between the conceptualisations reflects, on the one hand, various disciplinary approaches (philosophical, economic, medical, social, pedagogical, psychological, etc.) and, on the other hand, the different epistemological orientations that enhance, in the definition of quality of life, the objective conditions or, on the contrary, the detection of subjective indicators.

Within these conceptual frameworks, some authors focus their attention mostly on the objectively measurable aspects, for example, living conditions related to physical health, living environment, social relationships, income and work activity (Layte, Sexton and Savva, 2013; Landesman, 1986), whereas others take into consideration aspects related to subjectivity and satisfaction of the personal condition, psychological well-being, aspirations, values and expectations of people (Brown and Brown, 2009; Borthwick-Duffy, 1992).

Recent scientific acquisitions lead us to consider the quality of life as a complex construct that includes a plurality of relevant areas, both objective and subjective. It is interesting to note how, at the end of the nineties, perspective proposals of synthesis between these two possibilities of quality of life, the objective and the subjective areas, appeared. This position is represented by the early studies of Brown (1989). The author examined both dimensions in the life of adults with disabilities. For the objective component, Brown highlighted the following aspects that could guarantee high levels of satisfaction:

- the presence of adequate physical environment characteristics;

- $\quad$ attention to food and health conditions of people with disabilities and

- the quantity and quality of training and the real support present within the structure. 


\section{Paths and Technologies in the Life Project of People with Disabilities: International Perspectives and Educational Potential}

Giaconi, Del Bianco

Concerning the subjective dimension, the author takes the following into consideration:

- The perception that people with disabilities has, for example, relating to support, health, involvement in the community, etc.;

- the expectations that people with disabilities have and

- the level of satisfaction of people with disabilities.

This conceptualisation marks a relevant and interesting progress in the scenario of quality of life paradigm. As a matter of fact, for disabled people, the quality of life is certainly influenced by the presence or the absence of some objective requirements; however, at the same time, it is closely connected to the expectations and the level of satisfaction that the person manifests in relation to his or her current life's conditions.

In our opinion, the innovative aspect presented in Brown's proposal considers quality of life determined both by the gap between desires and needs satisfied and not satisfied and from the control that the person is able to exercise on his own environment.

To analyse the quality of life as a multidimensional phenomenon, Schalock and collaborators proposed the following key concepts: domains, indicators and descriptors (Schalock et al., 2002; Schalock and Verdugo Alonso, 2002). Quality of life is articulated in basic domains, defined as important areas or dimensions in the person's life. Quality of life domains are, for instance, emotional well-being, interpersonal relationships, material well-being, personal development, physical well-being, self-determination, social inclusion and rights (Schalock, Gardner and Bradley, 2007). These domains are key aspects to define the quality of life framework; however, the absence of possibilities of individual development, significant social relationships, material well-being, etc. in the life of a person will certainly influence the quality of his or her life. Even in the lives of adults with disabilities, the absence of an effective relationship network and the lack of participation in the community life in which they belong to would greatly affect the possibility of satisfying living conditions. To overcome a mere abstract definition and therefore to operationalise the quality of life domains, the authors identified some indicators. These indicators characterise the individual dimensions of the quality of life, which are the specific conditions to take into consideration for each domain (Schalock and Verdugo Alonso, 2002, page 67). In other words, how is it possible to qualify the quality of life domains, for example, the domains of physical well-being and self-determination? In the first case, we refer to the assessment about the presence or the absence of adequate general health condition, correct nourishment, standards of personal hygiene, or significant recreational activities; in the second one, we try to evaluate the level of participation of the disabled person in the decision-making processes that concern daily aspects and his or her life. These are, therefore, indicators that characterise the domains of physical well-being and self-determination and that concretely allow us to specify the general meaning of these two quality of life dimensions. It is essential to remark that indicators, referred to the domains, can vary at the individual level in terms of values, importance and perception. For example, a person may have an objective and proven state of health but could perceive a general feeling of physical discomfort. Or even, within the domain of interpersonal relationships, a person might, in the course of his life, consider more important or give a greater value to friendships rather than to medical care and family relationships.

With reference to the recent meta-analyses, Schalock and Verdugo Alonso (2006) presented a systematic review of domains and indicators that come out from the analysis of various theories and research concerning the paradigm of quality of life. We report an exemplification of the domains and indicators in Table $1^{2}$.

Table 1. Example of domains and indicators (Schalock, Verdugo Alonso, 2006)

\begin{tabular}{ll}
\hline Domains & Indicators \\
\hline Social inclusion & Community integration, community participation, role, support, acceptance \\
Physical well-being & Nourishment, personal hygiene, health, health care, free time \\
Interpersonal relationships & Family relationships, friendships, work and social relationships, intimacy \\
Material well-being & Goods, property, employment, financial situation, housing, security \\
Emotional well-being & Satisfaction, self-concept, security, spirituality, happiness \\
Self-determination & Opinions and personal preferences, decision and choices, personal control \\
Personal development & Personal enrichment, personal skills and ability, realisation \\
Rights & Knowledge of rights, protection, privacy, respect \\
\hline
\end{tabular}

\footnotetext{
${ }^{2}$ The criteria for the indicator selection must be the following (Schalock, 2006): validity (to measure what the evaluators want to measure), reliability (agreement between subjects and different evaluators), sensitivity (to detect changes), specificity (to reflect the situations), sustainability (realism in economic terms and human resources available in extended temporal perspective), longitudinal evaluation (coherence between the indicators) and cultural sensitivity (to reflect the reference culture).
} 


\section{Paths and Technologies in the Life Project of People with Disabilities: International Perspectives and Educational Potential}

Giaconi, Del Bianco

Certainly, indicators are not sufficient to describe the specificity of people and environments of everyday life. Therefore, the indicators can be declined in different contexts and in specific situations through the identification of descriptors, behaviours or situations that are observable and relevant for the context of reference.

We take as exemplification the domain of self-determination, where it is possible to find the indicator of choice and decision. In this case, we could identify as descriptor the presence of options of daily activities, leisure time, meals, clothes, places to visit, people to attend, etc. These situations should be observed in the contexts of life, family or residential community, where the person with disabilities lives to understand which characteristics are relevant to the indicator of decision and choice, and then for the self-determination dimension of the person with disability. Identifying the descriptors completes the operationalisation process of quality of life domains. The recognition exercise of domains, related indicators and descriptors would refer directly to the evaluation of personal results, programmes and services related to people with disabilities in terms of quality of life (Brown and Brown, 2009; Schalock, Gardner and Bradley, 2007; Emerson et al. 2004). In accordance with identification and operationalisation phases of domains, a variety of research tools are constructed, such as questionnaires, indexes and interviews. As illustrated, these procedures are focussed on both the objective analysis of living conditions of people with disabilities and the detection of personal satisfaction with reference to the quality of life. Some perspectives individualise some transversal areas where to insert and consider the different dimensions of the quality of life.

Among these perspectives, we deem noteworthy to highlight the proposal made by Renwick and Brown (1996); moreover, at the international level, the University of Toronto project is frequently adopted by associations and organisations that deal, for example, with adults affected by the autistic spectrum disorder for the analysis of the quality of life. In the theory, the authors define the quality of life as the degree of satisfaction through which people take advantage of possibilities and opportunities considered important for their existence (Renwick and Brown, 1996). Within this definition, the authors develop the building of quality of life in three large transversal areas: being, belonging and becoming. These sections respectively indicate individual and specific characteristics of a person (being), the adaptation and the quality of integration in the contexts of belonging (belonging) and the planning and development of people in their span of life (becoming).

The macro area of becoming, on which we will focus our attention, is explicit on a practical, recreational and evolutionary level. For the practical area, domestic, school and work activities are the main reference indicators; for the recreational sector, the activities and resources from the point of view of free time are identified as relevant; for the evolutionary area, the lifelong learning and the ability to acquire skills that allow the person to improve relational aspects and the capability to adapt himself or herself in different environments and situations are considered as the indicators.

Furthermore in this direction, we propose the perspective of 3C's described by Cottini and Fedeli (2007). The authors present an analysis of the quality of life dimensions through three transversal aspects: centrality, control and continuity. The centrality allows us to appreciate if the structure and the educational interventions are oriented on the fundamental characteristics for the quality of life of disabled person. The transversal areas of control and continuity make it possible to assess whether these aspects are potentially controllable by the person and if they are present continuously over time during the life project.

Schalock and collaborators (2010) had implemented their proposal (2002) including the eight quality of life dimensions, outlined by them, within three transversal areas: independence, social participation and well-being. The independence transversal area concerns the domains of personal development and self-determination; the social participation transversal area involves the domains of interpersonal relations, social inclusion and rights and finally, well-being transversal area includes the dimensions of physical well-being, material well-being and emotional wellbeing.

We believe that the perspective of these studies turns to the individualisation of transversal areas; this is particularly meaningful for the analysis of the quality of the life of people with disability and for the evaluation of the educational projects. These researches not just make it possible to detect the relevant sections for an educational intervention, aimed at maintaining and implementing the quality of life levels, but furthermore allow general indicators to design and monitor, over time, the central characteristics for the quality of life (such as housing conditions and job placement) of adults with disabilities. The international guidelines, over the number of domains, consider these main dimensions applicable to all people and therefore, as far as we are concerned, also to people with disabilities (Brown and Brown, 2009; Reiter and Schalock, 2008; Schalock et al. 2002). In this regard, it has been shown that the characteristics of the quality of life, typically proper to others groups of population, also belong to people with disabilities (Emerson et al., 2004; Dennis, Williams, Giangreco and Cloninger, 1993). Certainly, we must bear in mind that there are some aspects 
strictly connected to the quality of life of people with disabilities that may concern health and cognitive development (Borthwick-Duffy, 1992, Flanagan, 1978), the type of disability, with the possibility of multi-disability and the person's age (Brown, 1988).

The fundamental domains are, therefore, the same for everyone, but the "content" can vary individually in terms of values and importance. Therefore, undisputedly, this position shows how these domains are evaluated differently by the person and how the value attributed to them changes during the course of life (Schalock and Verdugo Alonso, 2006, p.48, Campo, Sharpton, Thompson and Sexton, 1997), as well as the important role of experiences, of different "systems" and contexts that influence the lives (Schalock, Keith, Verdugo Alonso and Gómez, 2011, Petry, Maes and Vlaskamp, 2009, Schalock and Verdugo Alonso, 2002).

Furthermore, the quality of life does not refer to a fixed time (Renwick et al., 1998; Timmons and Brown, 1997) but covers the entire life span. The quality of life, in fact, is sensitive to a temporal dimension, since it, and its perception, potentially changes on the diachronic axis, during the different "times" of life, and on the synchronic axis, in the different spaces of the person's existence. We strongly believe that it is important for any scholar and any operator to identify the quality of life domains, indicators and descriptors. This exercise becomes essential for not using the various proposals analysed in a prescriptive way but for the application of quality of life construct in relation to the person and to the contexts.

Through this operating mode, it is possible, then, to proceed with the construction of observation and survey tools (questionnaires, observation grids, etc.) with the planning and the implementation of educational practices, designing the living environments, the right of participation and social inclusion, aimed to promote higher levels of satisfaction for disabled people.

\section{New perspectives and innovative potentiality for the quality of life of people with disability: the ambient assisted living}

To work within the quality of life paradigm, it is crucial to act in the direction of personal life path, especially if the person has a disability in terms of both residency and networks integrated in the community of belonging. It is necessary, therefore, to mention three significant aspects to avoid misunderstandings or simplistic readings related to this delicate theme. First, it must be remembered that the structuring of potential paths is based on the needs of a specific person with disabilities, in relation to his or her reference contexts and in line with his or her life project. Second, it is necessary to build meaningful "bridges" to prepare the person to live independently or in residential structures, avoiding clear conflicts between family life and external contexts to interpret these services as a shared choice toward the best quality of life. Finally, we would like to remind that although the studies taken into consideration highlight the differences in the quality of life between family life and life in institutions and among people living in services with small units compared to large structures (Lifshitz et al., 2008), the quality of life depends also on the ability of services to create significant networks with the family and on the professionalism of people to run and operate in the structures (Giaconi, 2012a). In the supporting network for the family and for people with disabilities, we find day-care rehabilitation centres and residential structures that can offer short-term or extended services. New perspectives are moving toward ambient assisted living or "assisted living environments" that, in our opinion, are proving to be an effective and efficient model of inclusion for adults with disabilities. An interesting perspective for the quality of life and the inclusion of disabled people is offered by the research of adequate and sustainable forms that allow people with disabilities, and also the elderly, to live at home ensuring safety and support in daily life activities and promoting autonomy in addition to active participation (Casazza et al., 2002).

Ambient assisted living is a programme launched by the European Commission (2007), oriented to raise levels of well-being of older people and vulnerable groups through the support of information, communication and technologies (ICT). Based on an interdisciplinary approach, it is therefore possible to experiment software and hardware solutions dedicated to environmental and personal levels, with the final goal of improving the quality of life of older people or people with disabilities. For example, we can consider the wearable Microsystems for Ambient Assisted Living mobility-oriented and camouflage apparel (belt, watch, footwear), able to measure the dynamics of human movement and monitor physical activity, events such as fall, posture or walking. In other words, these are sensors that make it possible to detect any person's falls or irregularities at any time of the day or possible transformations and emergencies in the living environment. Numerous audio-video sensors or generic environmental sensors provide information about the daily activities of people and their behavioural conduct, including the detection of any alert indicators to family members or operators. Wearable sensors are also used to appreciate indices of qualitative activity performed from sleep 
to movement. Environmental sensors are also designed to monitor gas, electricity and opening and closing of doors and windows.

The research frontiers tend towards virtual communities of mutual help (Rashidi and Mihailidis, 2013, p.58) to ensure that caregivers can monitor at distance and attend in case of need. In general, the complex articulation of the ambient assisted living system is aimed to the activity recognition and behavioural analysis, with particular reference to wearable sensors or video devices to detect physiological parameters and environmental sensors, for safety, ambulation and mobility in the environment of reference; to access and use tools such as armchairs and beds; for the management of prompt intervention requests; for the storage of a plurality of data for a synchronic and diachronic analysis and for processing and analysing information from the sensors for a general recognition, at quantitative and qualitative levels, of activities and behaviours. The objectives of ambient assisted living are inserted within the framework of quality of life. The purposes are in fact those of prolonging life in the personal environment of the person with disability or older adults, enhancing the possibilities of self-sufficiency, safety, mobility and autonomy with the environment and with the network of significant people. This dimension is perfectly in line with the new European Horizon 2020 perspective. There are remarkable national and international research programmes intended to support projects for the development of innovative solutions aimed to improve the quality of life of people with disabilities and older adults. These programmes aspire to guarantee the quality of life and reduce what could be the total costs for home or other kind of assistance, taking into consideration the percentages of the "ageing" Italian population. Specifically, the international panorama is rich of meaningful proposals and experiments, in most cases approved by the Active and Assisted Living (AAL) programme ${ }^{3}$, an applied research, development and innovation (R\&D\&I) funding programme, that develops projects related to ICT solutions, undertaken jointly by EU member states and countries and associated with Horizon 2020 and co-funded by the European Union. The AAL programme focussed the attention on new technological tools and system, based on ICT, and was able to support older adults, and also those with disabilities, effectively in their everyday lives. For instance, these products are designed specifically to alert the caregivers in case of danger or to make the daily gestures easier to reach, up to inclusion or social contact with the external world. These characteristics of services make the disabled person more comfortable within their living contexts and in this way raise the level of perceived quality of life. ICT-based solutions, products and system concepts that appeared on the international scene described later have been chosen by us in relation to the success that the project has achieved through the years, bearing in our mind the focus of assistive technologies used to improve all quality of life domains for adults with disabilities.

\subsection{The sensor: device to deal with physical problems}

Two main successful projects developed specific sensors capable of responding to the needs that people with physical disabilities could have: CapMouse and FEARLESS.

Norway, Sweden and Belgium, under the coordination of Brusell Dental AS, entered the AAL programme in June 2009, thanks to the innovative CapMouse project ${ }^{4}$. Their purpose, designed particularly for disabled older adults and those with spinal injuries, was to develop an effective non-invasive sensor oral mouse interface that is able to support them during their daily movements. Simple and intuitive lip movements allow the disabled elderly to use electronic devices, instead of using a computer mouse: thanks to this hands-free system, they can control a wheelchair, turn on and off lights, open doors or have the access to the computer programme. The technology, called LipIt, looks like any communication headset where a capacitive sensor provides a comfortable use. After having secured also US patents, the team moved to push this innovative tool into the real market; Brusell explains that the technology experienced, thanks to the CapMouse project, has provided a method for basic input into the computer, and for this reason, they are currently in talks with Sony and are approaching Google and Apple, getting closer to the production and the industrialisation.

Within the FEARLESS project ${ }^{5}$ (in the AAL programme from June 2011) managed by the Austrian Dr. Brandstötter and his European partners, mostly from a security and surveillance background, has been specially designed the Fearless Comfort System, adequate for older adults also with disabilities, with the aim to make them actively participate in society, staying in the environment they wish. The strength of the system is its "invisible presence"; in fact, people do not notice its presence because wearable devices are not necessary. The planned system has only one sensor unit alarm that is able to identify accidents that could happen at home: it is installed in the house and triggers an alarm when it

\footnotetext{
${ }^{3}$ http://www.aal-europe.eu/.

${ }^{4} \mathrm{http}: / /$ www.brusell-dental.com/aal.

${ }^{5}$ www.cogvis.at, www.fearless-project.eu.
} 
individualises any serious deviations of person's behaviour (e.g. less mobility) and contacts immediately the relatives or caregivers. "Fearless: Safety through Simplicity" is the main motto of the team, explaining that this sensor is easy to instal and design, concept illustrates are uncomplicated and compared with other solutions is straightforward and cheap, characteristics that makes FEARLESS a commercially viable product.

\subsection{Plural sensor services: the independent living}

The strategic combination of sensors has become increasingly essential for older people needing assistance. In this direction, numerous initiatives are designed to ensure independent living for all, respecting the criterion of the chronological order we mention: BESTA, Asura flats, SmartBo and Rosetta.

In 1995, Norway financed experiences for the planning, implementation and execution of intelligent home systems to support the neediest people, mainly people with dementia. Thanks to the research project, called "BESTA", the town of Tønsberg allowed the realisation of eight automated apartments. The requests were born from anxiety and fear constantly tested by relatives for the high risk of falls, fires and loss of their family members affected by dementia (Bjornebye, 2005). BESTA intended to show that automated homes can offer higher level of qualitative life for disabled people compared to nursing homes, adopting, therefore, the European installation bus (EIB) system to facilitate the work of the assistance staff and the daily life of the family. As a general rule, the devices installed into the eight Tønsberg apartments were the sensors on the main entrance, on the doors leading from the apartment to the garden, in the cooker monitor and in the bed for weight detection and the electric floor heating system. Different solutions were chosen individually by each resident, in cooperation with the family and the support staff. An element to underline is the active involvement of assistant staff and family members in the selection of devices and assistance provided by technology. The staff was aware of the positive effects of the combination of technology and personal care, declaring that the system was perceived as an additional element to increase safety in the workplace (Bjornebye, 2005).

The residential complex built in Madrid is presented as an innovative model for the quality of life and is intended for disabled people. It consists of four independent buildings connected to a ground floor, where all the general services are found, such as the dining room, a snack bar and offices. It can accommodate up to 43 people and is equipped with accessible services, offering the maximum of technological innovations in all its spaces. The "Asura flats" project takes its name from the town where the residential complex is built, a central area of Madrid. The main innovative feature of this building is that the people who live in their loft can design, furnish and customise it according to their tastes and needs and at the same time can take advantage of personal care services (De La Cruz, 2005). Each loft is fully automated and allows people with disabilities to be autonomous in their daily lives. Scrupulous attention is paid to the decoration, design and organisation of the spaces as they intend to pursue the goal of making the person feel at home: the environment must be pleasant and comfortable. Thanks to its structure, the residential complex is able to combine two aspects: on the one hand, privacy by providing spaces for individual use that allow for maximum personal autonomy and privacy and on the other hand, sharing through the creation of common areas, such as a restaurant, snack bar, laundry, infirmary and spaces for leisure activities.

The Rosetta project ${ }^{6}$ (started AAL in June 2009) has focussed its attention on devices that could cope with the problems of people with progressive chronic disabilities, for example Alzheimer's disease. The integrated system, ICT based, can prolong the time that the person could live in his own environment, thanks to a non-obtrusive sensory system that would be set inside the home.

The database, which the system creates, is calibrated on the subject and is able to monitor all the daily activities that the person usually does; in this way, caregivers or assistants can be informed on the course of the illness. Every routine is recorded in the database, and if there is any deviations from the usual behaviour (such as an accident or a fall), the system marks the risk and raises the alarm. Rosetta's teams (mostly from the Netherlands) were able to construct a viable roadmap for bringing their work to fruition, looking as well to restore some of the autonomy through chronic disability. Rosetta represents an ideal example of how a project can identify a problem and become a marketable product: existing products focus their attention on the specific needs of every singular phases of the disease; the challenge of Rosetta, designed as a very elaborate and flexible system, was to increase a combination of functionalities suitable for people during their stages of disabilities, able to offer awareness services for independent living and achieve the highest level of quality of life.

\footnotetext{
${ }^{6}$ www.aal-rosetta.eu, www.dutchdomotics.com
} 


\section{Paths and Technologies in the Life Project of People with Disabilities: International Perspectives and Educational Potential}

Giaconi, Del Bianco

The project SmartBo funded by the Swedish Handicap Institute ${ }^{7}$ is aimed at people with reduced mobility, sensory deficits or cognitive disabilities (developmental disabilities, brain injuries, dementia). It led to the creation, in 2010, of a two-room apartment on the ground floor of a five-story building, located in a suburb of Stockholm. The project focuses on ICT support devices and solutions realised with information technology and electronics. The goal of the project is to promote an independent and comfortable life for disabled people, regardless of the type of disability (Elger, 2010). In this direction, the functions of the apartment must be controlled and supervised, by caregivers, in order to guarantee safety for people with mild or severe disabilities. In selecting the most functional systems, the apartment equipment can be divided into two different classes: one common to all and the other one appropriated to each group - even to each disabled person. The first class includes basic systems that allow monitoring the functions in the house, for example, doors, locks, windows, electricity, water intakes and cookers. The second category consists of devices that allow supervision and control to people with disabilities through interfaces that are adapted to the individual. All computers in SmartBo are connected to each other in a wireless network, so the disabled person can move freely, also in a wheelchair, and control the apartment remotely. A large number of services are available to guarantee accessibility and full control.

\subsection{New strategies for interpersonal relationships: resources against loneliness}

Social connections to preserve and new community bridges to build allow people, also those with disabilities, to keep alive the domain of interpersonal relationships, an important component of the quality of life system. In this regard, technology can provide open access for older adults, ensuring them to be always in touch with the others. Two representative projects follow as examples: ConnectedVitality and Express2Connect.

Presence Display SME, from the Netherlands, takes into consideration loneliness, which older people or adults with disabilities could face due to decreased mobility, loss of parents and diminishing mental capacity, even more if they are older adults with mobility problems. This range of people can have challenges organising their social life and their daily activity as they desire, which puts them in a situation in which they rely on others. ConnectedVitality ${ }^{8}$ (starting date October 2010) has attempted to solve these problems by developing a specific technology, more sophisticated than the traditional system, that consists of a video communication network that is easy to use and accessible to everyone. The ConnectedVitality project has the scope to enhance the communication among people, allowing also immobile people to organise their social interaction in relation to their individual activity and needs, reaching in this way higher levels of quality of life.

The project aimed to develop "the second best connection", called YoooM, with a dedicated and large digital display to preserve all the necessary elements of distance communication, two cameras to allow natural multidimensional perspective and a simple touch interface to make possible shared actions, making the device suitable for the capabilities of older and disabled people and at the same time simplifying their environmental needs and communication tools.

The web service with the creative app Storyville was appositely produced by the Express2Connect project ${ }^{9}$, designed to stimulate and facilitate personal storytelling. Available on App Store-based communication is kept active, thanks to the Internet connection: photos, music and past experiences turn into the starting point to build relationships and talks between older adults, with the final aim to create new connection with others or maintain a dynamic social life. The Copenhagen Living Lab Society, started in 2010, focuses on helping people, mostly adults, also those with disability, to enriching their social lives, trying to develop a better awareness concerning human contact and preventing the inner experience of loneliness, usually related to dissatisfaction, by understanding usual life needs.

\subsection{Technology supports independence and inclusion}

Especially designed technology devices can come through personal autonomy and social participation to support older people, also those with disability, during their everyday life, drawing at the same time an improvement of their perceived quality of life. In this field, we present in brief Mylife project and DOMEO.

The service offered by Mylife ${ }^{10}$ is specifically studied for people with cognitive disabilities, with the intend to give them the possibility to access uncomplicated software solutions, furthermore personalised to their individual needs and

\footnotetext{
${ }^{7}$ www.independentliving.org.

www.connectedvitality.eu, www.yooom.com.

${ }^{9}$ www.express 2 connect.org, www.copenhagenlivinglab.com.

${ }^{10}$ www.karde.no/MYLIFE_english.html, www.karde.no.
} 
desires. The Internet-based service model, realised within the Mylife project, is thought as software (i.e. software freely available on Internet) designed for use with smartphone touchscreens to connect and serve primary end users with formal and informal caregivers. The solution is elaborated to maintain cognitive abilities always active, supporting at the same time autonomy, time orientation, sensory awareness, iterations with others and recreational activities. The success of the European trials in Norway, Germany and the UK (April 2011) helped families to overcome their fears, also if they were afraid in using technology, familiarising with this system during their daily routine. Memas, the intuitive software developed through the Mylife project, also recognises the importance of encouraging end users' cognitive abilities by sustaining socialization and enjoyable activities. A large number of services become available, such as newspapers, electronic device or Internet, and the person, in the inclusive context, does not feel alone.

The DOMEO project ${ }^{11}$ has designed mobility assistive and companion robots to propose a personalised domestic system, with the aim to increase the quality of life frame, as it is oriented to provide autonomy to older adults. ROBOSOFT in France entered the AAL programme in 2011, introducing assistive robotics into the domestic sphere for physical support or relationship, offering at the same time useful answers for vulnerable subjects who want to maintain their independence staying longer and safer at home. The DOMEO project successfully created two pilot devices: robuMATE and robuWALKER. The first one connects people with the world around, offering them entertainment activity and cognitive support, to remind them of meetings, scheduled programmes or the specific time they have to take their pills. The other one physically interplays with the subjects to support them during their movements and to assist them stand up, walk and sit, also observing their vital signs and sending this information to the emergency services, if necessary.

\subsection{Brain training: virtual reality}

Multiple uses of technological tools overcome perspectives of daily use, producing significant scientific results to help people with the rehabilitation or the implementation of weak cognitive functions. The Rehabilitation Gaming System (RGS) project ${ }^{12}$ moves towards this intent.

The Universitat Pompeu Fabra in Spain developed (using the AAL programme since 2009) a narrative virtual realitybased system in favour of the domestic rehabilitation, useful for physical difficulties, emotional problems and cognitive and language disorders originated by brain injury. The RGS is an innovative integrated ICT-based device focussed on the brain's work. This system deploys a personalised and particular deficit-oriented training game, able to mix up movement execution and correlate actions transmitted by virtual limbs. The project wants to develop and integrate the hardware and software within the rehabilitation setting, creating as well theoretical and empirical bases useful for the diagnostics and rehabilitation methods at neuronal and functional impact. The price of neural rehabilitation is very high, while successful treatment to help all the stakeholders is restricted to physiotherapy, drug and occupational therapy. For these reasons, the highly effective virtual reality tool, created by the RGS, is now used in numerous hospitals and poststroke care centres in Europe.

Synthetically, a table in the following represents several projects, digital categories of tools and their quality of life's implications in the above-mentioned disabled people. The aim is to stress and have a visual representation about the main features of each tool supporting the building of qualitative life in disabled people and the pedagogical aspects related to them.

Table 2. Projects

\begin{tabular}{lll}
\hline Projects & Categories of tools & Main quality of life's domains involved \\
\hline CapMouse, FEARLESS & Sensors & Physical well-being \\
BESTA, Asura flats, SmartBo, Rosetta & Plural sensor services & Material well-being, self-determination \\
ConnectedVitality, Express2Connect & Display; web service & Emotional well-being \\
Mylife project, DOMEO & Technology devices & Social inclusion \\
Rehabilitation Gaming System (RGS) & Virtual reality & Personal development, physical well-being \\
\hline
\end{tabular}

\footnotetext{
${ }^{11}$ www.aal-domeo.eu, www.robosoft.fr.

${ }^{12}$ http://rgs-project.upf.edu, www.upf.edu/en.
} 


\section{Pedagogic reflections and lines of inclusive planning}

The complex framework of the quality of life for disabled adults widens the reflection to different levels of pedagogical perspective. Remaining anchored to the real person's needs, with regard to both objective and subjective aspects, strategic and tangible proposals are mentioned to support the person during his or her meaningful and qualitative life project. In particular, we take into consideration the binomial quality of life - ambient assisted living, and plural features that intersect transversely to the construct of quality of life. Conclusive reflections close (and open) the discussion. In the scenario of the quality of life and the ambient assisted living, some pedagogical reflections, for the design of a coherent life project for people with disabilities, should be carried out. The desirable course to be drawn and therefore to attain regards the possibility to achieve a better and quality lifestyle for vulnerable individuals. In this direction, it is necessary to rethink an integrated system that takes care of the adult with disability and his or family and is able to respond in a professional and planned way to the delicate transition phases from adolescence to adult life of the disabled person, who must be at the centre of his own project and therefore participate personally in the decisionmaking process towards the best condition of life.

In our view, the trajectories of life, also for people with disabilities, must be trajectories of meaning. This path cannot be followed if the service network stops supporting the family and the person with disabilities in the delicate transitional phases (Giaconi, 2012b). The shared choice of families, supporting caregivers and care organisations of a life path, acquires sense if there is the realisation of a meaningful project. This means that if there are conditions to prolong life situations in the family context, in assisted environments, this path should be contemplated and followed with the right professionalism and with non-generic and standard, but personalised, situations. We believe that ambient assisted living should be an option in some cases, in which the use of technology and innovative new systems could create a uniformed playing setting for all; however, strategies with specifically shared motivations and individualised route must be undertaken to avoid the risk of being disoriented during the phases of change and passage. Additionally, in our vision, the focus should be on taking into account new ways to see the concept of ambient assisted living and technology services in general, not only oriented to promote a better condition of "physically" accurate life. Applications of technology-based solutions are flexible and variegated in forms; therefore, it is possible to exploit these potentialities, calibrating for each person the most appropriate technological system, with the final aim to enable every person to live his life to the fullest in a qualitative way. The implementation of devices, remotely manoeuvred, to control physiological parameters and behaviour and to support the preservation of health and functional capabilities, must not be the only component to be considered fundamental to improve the quality of life framework of people with disabilities. We propose to encourage more and more the development of procedures and instruments intended to prevent social exclusion and able to support the preservation of the multifunctional network around the individual, products not only needed but also wanted, taking into consideration people first, with their wishes and aspirations, because the environment is made of not only comfort dimensions but also relationships. Just a few of the technological solutions are thought to increase subjective quality of life domains, such as social inclusion and interpersonal relationships; on the contrary, they are mostly oriented in a specific objective way (i.e. physical well-being). The exclusion or the partial consideration of certain areas, which are significant for all humans, can lead to the loss of the global sense of well-being, which the person cannot perceive as truly complete. The living environment in its entirety should be perceived by the disabled person as supportive, an authentic point of reference, so that technological devices can expand to become suitable to maintain constant consolidated social relations, increasing participation in social life. In such direction, the "assistive" environment can be designed and furnished with technological devices that allow people to be connected with the world around them, ensuring as well inclusive perspective of participation.

In the international scientific literature, Buntinx and Schalock (2010) proposed an organic assessment framework that takes into consideration the models of human functioning and the quality of life frame and supports construction. In this perspective, the relevant aspect regards the shift of the evaluation focus from the subjects' deficits and disabilities to the support necessary for people to lead an independent life and implement their quality of life. In other words, the multidisciplinary evaluation is oriented to knowing the person from the point of view of intellectual abilities, adaptive behaviour, participation, interactions and social roles, health and context. However, at the same time, it considers the needs of the subject and the areas of intervention and therefore the support necessary for the quality of life of disabled people. This planning provides to plan targeted programmes, commit resources and prepare support aimed at improving the individual condition of the person and the quality of life.

The connection between functioning, quality of life and educational interventions is the aspect of greater interest, guiding people in the community to which they belong. Therefore, the first aspect to be rethought concerns the 
professional practice of planning, which in the case of structuring assisted living environments is carried out from an interdisciplinary perspective, where, however, the purpose of the inclusion must always be present with the customisation of the best way that could guarantee the quality of life for the person. We begin from pedagogical criticalities that can be found in the realisation of life projects for adults with disabilities.

First, there is the risk of a fragmentation of the various educational interventions in the different steps, from one school to another but even more from the exit of the school system, to be introduced into educational and rehabilitative territorial structures. This passage involves a loss of the historical dimension of the educational intervention, which risks stirring in the "present eternity", where the educational objectives disappear and reappear over the different years of life. In recent years, there are numerous positions that have strongly reiterated the need for a lifespan perspective for people with disabilities, an approach that invests the whole arch of the existence. Attention is therefore directed towards an educational perspective that recognises the necessity of continuous and constant educational interventions. Effective educational paths aimed to achieve better living conditions, since the first school approaches, have a significant impact on development opportunities and consequently on quality of life during the adult phase. Second, a simple linear view is often used in the design of the project of life, where the intervention is constructed on the basis of a simplistic reading of operation, functional diagnosis and functional dynamic profile. However, we strongly believe that it is not enough to build the objectives of educational projects on the basis of simple individual functioning. The attended individual functioning, promoted with the interventions, corresponds to a level of adaptation to the context of the structure, but in such direction is possible to lose the inclusive perspective. Very often, there is a misalignment between the functioning and the needs of the person, detected by the multidisciplinary assessment using the quality of life domains. Third, after the loss of the family, the option of the ambient assisted living solution is not commonly considered; instead, emergency solutions are taken, usually of a welfare nature, which involve admission in large healthcare facilities.

Therefore, from an ecological and longitudinal point of view, we want to make evident the possibility of aligning the life project of a person with disabilities with the paradigm of the quality of life, considering that general reflections take shape in reference to the person himself or herself and to the interactions with his or her contexts of reference. The scientific literature in didactic planning specifically focuses on the concept of alignment (Biggs, 2003, Laurillard, 2012, Rossi, 2011). We believe that this concept is central in educational planning and in the life projects of disabled people, as a strategic way to implement actions aimed at implementing the quality of life. In an educational project, there are many dimensions that must be aligned, and it is the task of professionals to ensure this alignment, with co-participation, also as educators, in the design of assisted living environments.

Among the different forms of alignment (Giaconi, 2014), we consider the following two. The first form concerns the alignment between the functional conditions of the person, noticed by the multidisciplinary assessment, with the quality of life domains. The second takes instead into consideration the alignment between the objectives obtained from different interventions, with the purpose to build together with the person the path for his or her own inclusion and for the recognition of his or her adult identity status.

Initially, we take a look at the first form of alignment. In taking care of adults with disabilities, the initial assessment allows to appreciate the condition of the person's potentialities, in terms of strengths and limitations, within their own contexts of reference. What emerges from the clinical and functional diagnoses cannot be compared directly with the quality of life domains, in order to detect whether the person reaches or not good quality levels in the specific dimensions of his or her daily life. Within the framework of special pedagogy, it is extremely interesting to see how educational issues of disability are unequivocally related to contextual aspects, as well as personal peculiarity. In this perspective, we observe, in fact, a significant discrepancy between the functional condition of the person and the typical levels of quality of life in the social, cultural and practical contexts of reference (Schalock et al., 2007). From this gap emerge, within the history of the person and the context of reference, the actual needs of the person and the support that people need to increase the level of independence of their lives, improving their quality. Consequently, a life project must start from support needs, which correspond to areas in which the person does not reach an adequate and satisfying quality of life. From this point of view, the processes of identifying the priorities for intervention and mapping of resources and the indispensable supports, by ensuring a qualitatively adequate and functional condition for human wellbeing, are simplified. On the same level, another type of alignment is also involved: the alignment between desires, expectations and needs perceived by the person with disabilities, relatives and the structure operators. In a systemic and ecological vision, it is indeed necessary to promote not only the involvement of adults with disabilities but also the participation of their families, educational agencies, contexts and reference services. The underestimation of this phase of alignment, which concerns, for instance, the comparison of the different subjects' expectations involved in the project of life of the disabled adult, could compromise the implementation of an integrated intervention system useful 
for the person's quality of life, also weakening the desirable co-planning dynamics. On the contrary, a strategic work intentionally carried out to overcome possible discrepancies, which could appear among abilities possessed, desires, expectations, objectives and performances required by the reference contexts, aimed at ensuring greater possibilities of co-responsibility and co-participation in the adult life project with disabilities, also in the direction of ambient assisted living solutions.

The second form of alignment concerns the alignment of different objectives. The objectives concerning the life project and the different levels of intervention (clinical, rehabilitative, educational and social) must be oriented towards promoting the improvement in the quality of life, favouring the conditions for a life suited to its context (Cottini, 2008, p. 35). The main goals must be chosen from skills oriented to adult autonomy (Ianes and Cramerotti, 2009), skills related to self-determination, the maintenance of good network support, conscious management of one's own health, free time, employment, identity dimension and identity and self-design dimensions and "life skills". These objectives must be relevant and significant in the life project of the person with disabilities and must be functional to the needs of daily life and real contexts to promote social participation in family, friendship and community networks (Adams et al., 2006). The aims should also tend to expand self-determination levels ${ }^{13}$. Wehmeyer et al. (2010) have shown that selfdetermination is independent of the available environmental conditions and operating conditions. International research (Lachapelle et al., 2005) has shown that self-determination is a crucial dimension to improve the quality of life and promote social inclusion. A high level of self-determination increases the possibility of having a positive adult life, for example, in terms of work and autonomous and independent life $\mathrm{e}^{14}$.

In evaluating educational projects, we can formulate guiding questions for professionals who also want to think about the promotion of assisted living environments. In such direction, Adams et al. (2006) proposed an evaluation scheme of educational projects, focussed the attention on indicators and for each of them found specific descriptors (Table 3).

Table 3. Evaluation scheme of educational projects

\begin{tabular}{ll}
\hline Indicators & Descriptors \\
\hline Relevance & Are rehabilitation goals relevant and meaningful in the individual life project? \\
$\begin{array}{ll}\text { Observability } & \text { Are the objectives translatable into observable behaviours? } \\
\text { Appropriateness } & \text { Is the educational project appropriate to the subject chronological age and to his health conditions? } \\
\text { Functionality } & \text { Is the educational project functional to the needs of daily life and significant compared to the contexts of belonging? } \\
\text { Temporality } & \text { Is the educational project temporally weighted and limited in time to verify if it has been reached? } \\
\text { Monitoring } & \text { Is the educational project constantly monitored? Also in terms of improvements or worsening? } \\
\text { Measurability } & \text { Is the educational project qualifiable and quantifiable? } \\
\text { Realism } & \text { Is the educational project reachable in relation to available human and material resources? } \\
\text { Inclusion } & \text { Is the educational project functional to increase autonomy, self-determination, and empowerment of the person; is } \\
& \text { there alignment with his wishes? } \\
\text { Participation } & \text { Does the educational project promote social participation and relationships with friends, family and social network? }\end{array}$ \\
\hline
\end{tabular}

The complexity of taking care adults with disabilities poses different challenges to special pedagogy. The first one is certainly rethinking an overall strategic plan capable of supporting and guaranteeing a life project that responds to the needs of the person and is oriented towards achieving the best possible condition of life. Reflection, even if related to the adult phase, cannot avoid taking into consideration the different evolutionary phases and pedagogical emergencies throughout life. At the same time, it should be necessarily characterised as a co-participated and shared project action: the disabled person and his family must be at the centre of a real network of integrated systems aimed at the full realisation of the life project. In the sign of this co-responsibility and design commitment also towards new models of inclusion, such as assisted living environments, keywords become planning, continuity and training. A shared planning allows the quality of life project to be continuous and not fragmented and the whole community to "look forward"

\footnotetext{
${ }^{13}$ International research has promoted in this direction procedures of self-determination evaluation for people with disabilities, both as tools for selfevaluation and external evaluation. For example, we report the evaluation scales for the self-determination by Soresi and Nota (2007). The evaluation scale examines self-determination in relation to the activities of daily life, for example if the person with disability can decide how to spend money, if he or she expresses his or her emotions, if he or she freely devotes himself or herself to the activities to be carried out during the day or if he or she can usually make his or her own choices.

${ }^{14}$ Therefore, the same level of life satisfaction is closely linked to the level of self-determination (Wehmeyer, 2002). For people with disabilities, this example is even more pronounced.
} 
projecting towards alignment between functions and relevant dimensions in everyday life, in other words, an alignment among past, present and future, intentionally oriented towards the full realisation of adult identity and quality of life. Only in this perspective, we can think of transforming the different life trajectories into a real and concrete path of meaning for the person and his family. Continuity guarantees an intentional synergy of educational interventions, which certainly change over time and in reference to the subject's needs and age but anticipate and support the different transitional phases in a time and a space that, overall, make the sense of what was previously done and how can be done to accompany the construction of the identity of the person with disability. If the training, supported by appropriate devices anchored to educational practices and by planning projects, is aimed to the reflection on the professional attitudes, it becomes the way to guarantee a real process of professionalisation and change in the care of disabled adults and their families.

\section{References}

Adams L. et al. (2006), "Individual Planning: An Exploration of the Link Between Quality of Plan and Quality of Life", British Journal of Learning Disabilities, 34, pp. 68-76.

Andrich, R., Gower, V. e Converti R.M. (2007), The DAT Service, an integrated approach to improve independence at home. In Eizmendi, G., Azkoita, J.M, Craddock G. (eds): Challenges for Assistive Technology, Amsterdam: Ios Press, 579-583.

Andrich, R e Pilati, G. (2008), Le tecnologie assistive nel progetto di autonomia della persona con disabilità: suggerimenti di buona prassi, Fondazione Zancan Onlus e Fondazione Don Gnocchi Onlus, in: www.portale. siva. it

Biggs J.B. (2003), Teaching for quality learning at university, Open University Press, Buckingham.

Bjornebye S. (1997), The BASTA Flats in Tonsberg, Using Technolgogy for people with dementia, Human factors Solutions, Oslo.

Blackorby J., Knokey A., Wagner M., Levine P., Schiller E., Sumi C. (2007), What makes a difference? Influences on outcomes for students with disabilities, Menlo Park, SRI International, CA.

Borthwick-Duffy A. (1992), "Quality of Life and Quality of Care in Mental Retardation”, Disorders of Human learning, Behavior and Communication, pp. 52-66.

Brown R.I. (Ed.) (1988), Quality of Life for handicapped people, Croom Helm, London.

Brown R.I. (1989), “Aging, disability and quality of life: a challenge for society”, in Canadian Psychology, 30 (3), pp. 551-559.

Brown I., Brown R.I. (2009), "Choice as an aspect of quality of life for people with intellectual disabilities”, Journal of Policy and Practice in Intellectual Disabilities, 6, pp. 11-18.

Buntinx W.H.E., Schalock, R. L. (2010), "Models of disability, quality of life, and individualized supports: implications for professional practices", Journal of Policy and Practice in Intellectual Disabilities, 7 (4), pp. 283-294.

Casazza S. et al. (2002), Anziani. Tra bisogni in evoluzione e risposte innovative, FrancoAngeli, Milano.

Cambridge P., Carnaby S. (2000), Making it Personal: Providing Intimate and Personal Care for People with Learning Disabilities, Brighton, Pavilion.

Campo S.F., Sharpton W.R., Thompson B., Sexton D. (1996), "Measurement characteristics of the quality of life index when used with adults who have severe mental retardation", American Journal on Mental Retardation, 100, pp. 54650.

Cottini L., Fedeli D. (2007), “Invecchiamento e Qualità della Vita. La QdV come quadro concettuale per l'analisi e per l'intervento nel decadimento cognitivo delle persone con ritardo mentale”, AJMR, American Journal on Mental Retardation (Italian Edition), 5 (3), pp. 375-382.

Cottini L., Fedeli D., Leoni M., Croce. L. (2008), "La Supports Intensity Scale nel panorama riabilitativo italiano Standardizzazione e procedure psicometriche”, American Journal on Mental Retardation, Italian Edition, 6, 1, pp. 21-38.

Dennis R., Williams W., Giangreco M., Cloninger C. (1993), "Quality of life as context for planning and evaluation of services for people with disabilities”, Exceptional Children, 59, pp. 499-512.

Emerson E., Hatton C., Thompson T., Parmenter T. (2004), The International Handbook of Applied Research in Intellectual Disabilities, Wiley, Chichester, England. 
Felce D., Perry J. (1996), “Exploring current conceptions of quality of life”, in I. Renwick, I. Brown, M. Nagler (Eds.), Quality of life in health promotion and rehabilitation: Conceptual approaches, issues, and applications, Sage, Thousand Oaks, CA, pp. 51-62.

Felce D., Bowley C., Baxter H., Jones E., Lowe K., Emerson E. (2000), “The effectiveness of staff support: evaluating active support training using conditional probability approach”, Research in Developmental Disabilities, 21 (4), pp. 243-255.

Flanagan J.C. (1978), “A research approach to improving our quality of life”, American Psychologist, 33, pp. 138-147.

Giaconi C. (2012a), Nella comunità di Capodarco di Fermo: Dalle pratiche all'assetto pedagogico condiviso, Armando, Roma.

Giaconi C. (2012b), Disability, Citizenship and Democracy from Life Plan to Social Inclusion, Civitas educationis. Education, Politics and Culture, vol. 1, n. 2, pp. 91-104.

Giaconi C., Rodrigues B. (2014), “Organization of time and space for the inclusion of subjects with autism”, Educação \& Realidade, vol. 39, n. 3, pp. 687-705.

Ianes D., Cramerotti S. (2009), Il Piano educativo individualizzato - Progetto di vita (nona edizione) - vol. 2 - Raccolta di materiali, strumenti e attività didattiche, Erickson, Trento.

Lachapelle Y., Wehmeyer M.L., Haelewyck M.C., Courbois Y., Keith K.D., Schalock R.L. et al. (2005), “The relationship between quality of life and self-determination: an international study", Journal of Intellectual Disability Research, 49, pp. 740-744.

Landesman S. (1986), "Quality of life and personal life satisfaction: Definition and measurement issues", Mental Retardation, 24, pp. 141-143.

Laurillard D. (2012), Teaching as a design science, Routledge, London.

Lifshitz H., Merrick J., Morad M. (2008), "Health status and ADL functioning of older persons with intellectual disability: community residence versus residential care centers", Research in Developmental Disabilities, 29, pp. 301-315.

Maes B, Lambrechts G., Hostyn I., Petry K. (2007), "Quality-enhancing interventions for people with profound intellectual and multiple disabilities: a review of the empirical research literature", Journal of Intellectual and Developmental Disability, 32 (3), pp. 163-78.

Morini, A. e F. Scotti, (2005). Assistive Technology. Tecnologie di supporto per una vita indipendente, Santarcangelo di Romagna: Maggioli Editore.

Panek, P., Zagler, W., Beck, C. e Seisenbacher, G. (2001). Smart Home Applications for disabled Persons - Experiences and Perspectives, EIB Event 2001 - Proceedings, 2001, 71-80.

Penne A. et al. (2012), "Staff interactive style during multi-sensory storytelling with persons with profound intellectual and multiple disabilities", Journal of Intellectual Disability Research, 56 (2), pp. 167-178.

Petry K., Maes B., Vlaskamp, C. (2009), "Psychometric evaluation of a questionnaire to measure the quality of life of people with profound multiple disabilities (QOL-PMD)”, Research in Developmental Disabilities, 30, pp. 13261336.

Rashidi P., Mihailidis A. (2013), “A Survey on Ambient-Assisted Living Tools for Older Adults”, IEEE Journal of Biomedical and Health Informatics, vol. 17, n. 3, pp. 579-590.

Reiter S., Schalock R.L. (2008), "Applying the concept of quality of life to Israeli special education programs: a national curriculum for enhanced autonomy in students with special needs", International Journal of Rehabilitation Research, 31, pp. 13-21.

Renwick R., Brown I. (1996), "Being, belonging, becoming: the Centre for Health Promotion model of quality of life", in R. Renwick, I. Brown, M. Nagler (Eds.), Quality of Life in Health Promotion and Rehabilitation: Conceptual Approaches, Issues, and Applications, Sage, Thousand Oaks, CA, pp. 75-88.

Röcker, C., Ziefle, M., \& Holzinger, A. (2011), Social Inclusion in Ambient Assisted Living Environments: Home Automation and Convenience Services for Elderly User. Proceedings of the International Conference on Artificial Intelligence, 1, $55-59$.

Rossi P.G. (2011), Didattica enattiva, FrancoAngeli, Milano.

Schalock R.L. (2000), "Three decades of quality of life", Focus on Autism and Other Developmental Disabilities, 15 (2), pp. 116-128.

Schalock R.L., Bonham G.S., Marchand C.B. (2000), “Consumer based quality of life assessment: A path model of perceived satisfaction”, Evaluation and Program Planning, 23 (1), pp. 77-87. 
Schalock R.L., Brown I., Brown R., Cummins R.A., Felce D., Matikka L., Keith K.D., Parmeter T. (2002), "Conceptualization, Measurement, and Application of Quality of Life for Persons With Intellectual Disabilities: Report of an International Panel of Experts", Mental Retardation, vol. 40, n. 6, pp. 457-470.

Schalock R.L., Verdugo Alonso M.A. (2002), Handbook of quality of life for human service practitioners, American Association on Mental Retardation, Washington, DC.

Schalock R.L., Verdugo Alonso M.A. (2006), Manuale della Qualità della Vita. Modelli e pratiche di intervento, trad. it., Vannini, Brescia.

Schalock R., Gardner J.F., Bradley V.J. (2007), Quality of life for people with intellectual and other developmental disabilities: Applications across individuals, communities, and systems, American Association on Intellectual and Developmental Disabilities, Washington, DC.

Schalock R.L., Verdugo Alonso M., Gómez L.E. (2011), "Evidence-based practices in the field of intellectual and developmental disabilities: An international consensus approach", Evaluation and Program Planning, 34, pp. 273282.

Stephanidis, C. (2011), Ambient Assisted Living and Ambient Intelligence: Improving the Quality of Life for European Citizens. In ERCIM News, 87, 2-3.

Thompson W.W., Zack M.M., Krahn G.L. Andresen E.M., Barile J.P. (2012), "Health-Related Quality of Life among older adults with and without functional limitations", American Journal of Public Health, 102, 3, pp. 496-502.

Timmons V., Brown R.I. (1997), "Quality of life issues for children with handicaps”, in R.I. Brown (Ed.), Quality of life for handicapped people, Second Edition, Stanley Thomas, Cheltenham, England.

Wehmeyer M.L. (1992), "Self-determination and the education of students with mental retardation", Education and Training in Mental Retardation, 27, pp. 302-314.

Zappaterra T. (2013), Domotica e disabilità negli ambienti di apprendimento. From the project FORM@RE, 13, $17-26$.

Zijlstra H.P., Vlaskamp C. (2005), "Leisure provision for persons with profound intellectual and multiple disabilities: Quality time or killing time?”, Journal of Intellectual Disability Research, 49 (6), pp. 434-448. 